\section{Información \\ La protección de los pueblos de colonización}

Juan Antonio Fernández Naranjo

Arquitecto. Delegación de Cultura de Sevilla

\section{Introducción}

En estos momentos se está poniendo en crisis el concepto de patrimonio histórico como algo cerrado, limitado y limitable, entendiéndose que las interrelaciones entre los distintos valores que pueden apreciarse en un bien cultural van más allá que la simple adscripción a unas figuras concretas de caracterización, ya sean jurídicas, técnicas o instrumentales. Por lo tanto estudiemos un bien, una entidad patrimonial o cultural, una realidad evidente, y veamos, tan sólo, cuáles son sus valores y con ello considerar si pertenece a ese grupo de elementos, el patrimonio histórico, que una colectividad reconoce como parte de su bagaje cultural con el cual se identifica, sin necesidad de introducirlo en un apartado concreto cerrado y excluyente.

Indudablemente esta nueva visión participa de la idea de territorio, que incluso se incorpora como un valor en sí mismo, como fruto que es también de la acción del hombre; sobrepasa así el mero hecho topográfico del marco donde toda actividad se desarrolla, de manera que hoy no se entiende ya el patrimonio histórico si no se le incorpora este concepto espacial, que llega a trascender a otros ámbitos como el temporal, o el cultural, en su concepción más abstracta. Se demuestra así, una vez más, cómo el patrimonio cultural no es un concepto cerrado, en cuanto que se pueda pensar en que este patrimonio es el que es, y no existe posibilidad de que se acreciente. Sin embargo, asistimos a nuevos hallazgos, investigaciones esclarecedoras sobre bienes que creíamos conocer, la incorporación de nuevas creaciones de las artes plásticas y otros conceptos que se van sumando a la consideración de valor patrimonial como puede ser éste del territorio o los ámbitos culturales.

Los pueblos de colonización se introducen plenamente en este debate, pero no sólo ellos, sino otras poblaciones que pueden ser entendidas como un grupo dotado de unos valores patrimoniales que van más alla de la simple adición de aquéllos que pudieran poseer de forma individual, de aquí las iniciativas de protección de las Nuevas Poblaciones de Sierra Morena, y no sólo localidades, sino elementos como las torres vigía o el patrimonio ligado a Juan Ramón Jiménez, los lugares colombinos y otros muchos.

En este estado de cosas es donde podemos contemplar con mayor amplitud el tema que nos ocupa, teniendo en cuenta que estamos ante un hecho concreto que es el de la colonización de un territorio ligado a la explotación agrícola, que como tal colonización participa de todo un recorrido histórico y conceptual muy ligado al de los asentamientos de nueva factura, a la ciudad ideal en definitiva. Por lo tanto, aunque nos estamos refiriendo a los pueblos, la acción territorial es en realidad la colonización en sí, los pueblos son los asentamientos concretos y son por ello parte de la referida acción territorial.
La idea de acotar el estudio a un período temporal concreto, determinado y muy reciente, 1940 - 1971 dentro del periodo franquista, aparte de estar basada en las indudables razones de unidad y homogeneidad del grupo, no debe suponer que se entienda como un hecho aislado sino que, además de la carga teórica, conceptual o ideológica, es fruto de experiencias anteriores que como antecedentes inmediatos claros, no sólo deben ser tenidos en cuenta, sino que deben participar claramente de las conclusiones a que pueda llegarse.

La cuestión sobre la que se pide que aporte mi visión es el de la protección que desde la legislación de patrimonio histórico, y en nuestra Comunidad Autónoma ${ }^{1}$, se puede ofrecer a estas poblaciones o mejor, introduciendo el valor del territorio, este ámbito patrimonial. Para ello vamos a estudiar qué cuestiones se plantean.

\section{Los poblados de colonización como Patrimonio Histórico} El primer tema es cualitativo. La consideración de los poblados de colonización como patrimonio histórico es absolutamente innegable, y otros lo argumentarán más extensamente, pero no es la parte fundamental de estas páginas que deben tener como hipótesis de partida su clara pertenencia a nuestro patrimonio histórico.

\section{De sus expedientes}

El segundo tema es en qué figura jurídica podría encuadrarse este grupo, que con lo que he tratado de exponer al principio de estas líneas entiendo que no tenemos un lugar claro donde ubicarlo en la actual legislación de patrimonio histórico, tan sólo haciendo una interpretación muy amplia de Conjunto Histórico tendría una incómoda cabida en esta figura ${ }^{2}$, teniendo en cuenta que, aunque hablamos de pueblos de colonización en general, éstos obedecen a momentos distintos y áreas geográficas diversas y acotadas, correspondientes a las zonas que se iban dotando de sistemas de regadío a través de la construcción de los correspondientes pantanos, canales y acequias de distribución, verdadero sistema de irrigación que vertebra las tierras a colonizar. Serían pues expedientes distintos cuya formalización también entrañaría algún problema como es que puede darse el caso de que el ámbito a considerar exceda, no sólo del municipio, sino de una sola provincia, unidad sobre la que está estructurada la acción administrativa, sobre todo, si estamos en el caso de provincias pertenecientes a distintas Comunidades Autónomas.

\section{Incremento cuantitativo}

El tercer tema es cuantitativo, indudablemente se incrementaría notablemente el número de Conjuntos Históricos, que aunque pudieran tener un expediente colectivo, cada población incluida en él debería tratarse como un conjunto independiente apreciando en cada uno de ellos la salvaguarda de los valores generales. 


\section{Información \\ La protección de los pueblos de colonización \\ Juan Antonio Fernández Naranjo}

Planes Especiales de Protección del Patrimonio Histórico Estos temas tendrian que conducirse para su protección a través de los instrumentos que la legislación de patrimonio histórico dispone, que no son más que los planes especiales de protección ${ }^{3}$, cuyo ámbito de aplicación son los municipios y ya hemos visto cómo un mismo expediente puede abarcar poblados ubicados en distintos municipios, ya que a partir de 1998 los poblados de coIonización pasan de depender del IARA (Instituto Andaluz de Reforma Agraria) a los Ayuntamientos que lo asumen asi dentro de sus propias competencias de administración territorial, convirtiéndose la mayoría de ellos en pedanías de aquéllos. Aún más complejo se vuelve este tema si se trasciende el ámbito provincial e incluso el de la Comunidad Autónoma; por lo tanto, salvo este último caso, tendríamos necesidad de redactar un Plan Territorial específico para ello, de manera que obligue a los municipios afectados a adecuar su planeamiento al mismo.

Esto, a pesar de tener un marco claro de desarrollo teórico, no deja de ser, en definitiva, una complicación dados los plazos de redacción, aprobación y convalidación de los planes, no sólo de la tramitación del Plan Territorial, sino de las modificaciones de los correspondientes planeamientos municipales y llegado el caso de su correcta aplicación y gestión por parte de los consistorios.

\section{La disciplina urbanística}

En este mismo sentido, y al estar estos poblados situados en el medio rural, los municipios que los contienen son menores y sabemos de las dificultades que este tipo de Ayuntamiento tiene para poder ejercer su competencia urbanística en toda su amplitud y potencia, especialmente en materia de disciplina urbanística.

\section{El periodo transitorio. Las Comisiones Provinciales de Patrimonio Histórico}

Siendo esto último complejo, la situación transitoria lo es más aún, ya que mientras no esté convalidado el planeamiento de protección, las licencias que se tramiten dentro del ámbito del bien deben ser autorizadas por la Consejería de Cultura, es decir por los o las titulares de las Delegaciones Provinciales previo informe de la correspondiente Comisión Provincial de Patrimonio Histórico. Por lo tanto, elementos pertenecientes a un mismo ámbito que trascienda la provincia, como ya hemos visto, pueden estar siendo informados por distintas Comisiones Provinciales, cuyo funcionamiento aún es bastante heterogéneo. A este aspecto hay que sumarle el tema visto anteriormente del considerable aumento de Conjuntos que significaría la inclusión de los pueblos de colonización, ya que una de las mayores cargas de trabajo de estas Comisiones está en la autorización de licencias en Conjuntos Históricos que no cuentan con planeamiento convali- dado de protección del patrimonio histórico ${ }^{4}$, con lo que se convertiria en un verdadero problema para el funcionamiento de las mismas. Hay que tener en cuenta, no obstante, que esa incorporación no se produciría de una forma única y sorpresiva, sino que sería de forma paulatina conforme se fueran resolviendo los expedientes de incoación. También una forma de suavizar este impacto podríamos encontrarlo en que los expedientes que se instruyeran para su incorporación al patrimonio histórico pudiera ya contemplar las directrices para su protección que, aunque tarden un tiempo en incorporarse al planeamiento, serían de aplicación directa por las Comisiones de Patrimonio Histórico.

\section{El período transitorio 2. La edificabilidad}

Dentro de este periodo nos vamos a encontrar con una cuestión bastante significativa como es que, durante el mismo, no se pueden crear alineaciones nuevas, agregar o segregar parcelas y, lo que mayores quebraderos de cabeza viene dando es que no se puede aumentar la edificabilidad ${ }^{5}$ y esto va a afectar muy directamente al concepto de parcela, de lo que trataremos más adelante de forma extensa.

\section{Qué proteger}

Estamos hablando hasta el momento de pueblos o poblados de colonización y, por lo tanto, estamos pensando en los meros asentamientos, pero el hecho colonizador es mucho más amplio, y retomando el inicio de estas líneas, es un hecho territorial; si bien los poblados concentran en ellos una mayor concreción constructiva, formal y artística, en cuanto que hecho arquitectónico, no son sólo estos núcleos los resultados de la colonización; se crean pantanos, canales, acequias, auténtico sistema de vertebración, como ya hemos dicho, que hace llegar el agua para el riego a las parcelas cultivables, para cuyo acceso se crea, a su vez, una red de caminos en paralelo al del sistema de riego. Por lo tanto, el territorio también se transforma, la parcela de cultivo se convierte en una unidad territorial muy presente ${ }^{6}$; asi pues la primera cuestión es cuál es el patrimonio histórico por proteger.

Podemos quedarnos en los pueblos pero no debemos olvidar que su razón de ser es la colonización de la tierra para su regadio, luego parece justificado extender la protección patrimonial al territorio sobre el que se actúa, así lo expresa también la legislación con las relaciones territoriales, los accidentes geográficos y los parajes naturales, pensados, no obstante, como elementos aparte ${ }^{7}$. En todo caso, debemos ver si esta ordenación territorial se corresponde a una idea de simple adecuación al terreno o, por el contrario, supone la superposición de una estructura que consigue ordenarlo claramente consiguiendo su mejor funcionamiento y por ello su dominio ${ }^{8}$. 


\section{Los poblados de colonización}

Dicho esto conviene centrarnos en lo que es la parte principal del tema que nos ocupa, los asentamientos, pero sin dejar de tener en mente, como en un segundo plano, el territorio, las tierras de regadio, de manera que nos permita hacer alguna oportuna referencia en paralelo. La legislación considera como más importante de los Conjuntos Históricos es su estructura urbana y arquitectónica así como las características generales de su ambiente ${ }^{9}$, es decir: el sistema viario, la manzana, la parcela con su forma de ocupación, sus alturas, sus relaciones espaciales internas y, entre el espacio vacío y el construido, el público y el privado, lo que supone, en definitiva, la arquitectura de la ciudad.

\section{La estructura viaria}

Esta estructura, en general y como todos los demás parámetros de las poblaciones, estaban regidas por el carácter de la vida agrícola, incluso con una jerarquización del viario con calles principales donde daban las viviendas y otras de servicio para los medios mecánicos, a las que daban los patios de labor. Pero además eran fruto de la ideología que los generaba y con ello la creación de un Centro, un lugar que focalizaba lo que toda ciudad del Régimen debía tener: la iglesia, la casa del partido, el ayuntamiento y las escuelas, esquema que puede adoptar múltiples formalizaciones en la práctica pero que en todas ellas está presente y es perfectamente identificable. Por lo tanto es un valor por proteger que además la legislación apoya, de manera que considera excepcional la remodelación de esta estructura urbana, aceptándola sólo en el caso de que implique una mejora de sus relaciones con el entorno territorial (de nuevo el territorio) o urbano o eviten los usos degradantes ${ }^{10}$.

\section{La parcela}

En este concepto se concentra la mayor parte de las cuestiones que hemos ido viendo hasta el momento. Le afectan muy directamente las condiciones del régimen transitorio hasta que el municipio cuente con un planeamiento de protección convalidado, es decir, no se puede agregar, no se puede segregar y no puede aumentar su superficie construida y, en definitiva, aunque cuente con dicho planeamiento, al ser la parcela una unidad claramente perteneciente a la estructura urbana para proteger por el plan, difícilmente podrá después superar las limitaciones anteriores, por lo tanto supondría la congelación de dicha parcela, tendríamos pues que estudiar esta situación muy detenidamente, junto con lo que veremos más adelante, a la hora de buscar una solución a este tema.

\section{La edificación. La casa}

La casa de los colonos supone también un valor tipológico importante ya que todas las de una misma población suelen ser similares. En general, cuentan con un espacio reducido para la vi- vienda, aunque suficiente para una familia del momento, pero muy generoso en dimensiones para los patios de labor pensados para poder desarrollar en ellos las faenas del campo que entonces necesitaban bastante espacio. Esta forma de ocupar la parcela y la evolución de las formas de vida hacia un mayor confort ha exigido la ampliación de la zona dedicada a vivienda a costa del patio de labor e incluso el aumento de población se ha hecho a costa del mismo, con lo que ha supuesto una segregación real de las parcelas con edificaciones de viviendas independientes en una misma parcela para otros miembros de la familia. El patio de labor ha perdido en parte la necesidad de tanto espacio: por un lado por la evolución de las técnicas y maquinarias de cultivo y, por otro, por la necesidad, como hemos visto, de acoger edificación de vivienda en su superficie; esta reducción del patio ha hecho necesaria la dotación de espacios para almacenaje en el exterior del pueblo por lo que conectamos con el problema del crecimiento tanto de vivienda como de almacenes e industrias.

Estas edificaciones además se construyen en un momento de expansionismo constructivo y en general se utilizan materiales tradicionales como el ladrillo y la incipiente industria del hormigón con unos estándares de confort y calidad mínimos, por lo que la degradación constructiva de las edificaciones es ya bastante acusada y su renovación va siendo cada vez más necesaria. Sin embargo, la legislación considera excepcionales las demoliciones ${ }^{11}$.

Como vemos, parcela y vivienda asumen conjuntamente varios de los graves problemas por resolver con respecto a la legislación de patrimonio histórico.

\section{El catálogo}

Otra cuestión es el valor artístico, estético o formal de las edificaciones, ya sea de forma singular como en conjunto y en general las formalizaciones conseguidas son bastante afortunadas ya que por esta vía tuvieron entrada los postulados del movimiento moderno que consiguió así adaptar a las formas de la arquitectura internacional la ideología tradicionalista. La legislación de patrimonio histórico resuelve este tema recurriendo a la figura urbanística del catálogo, con el que debe contar todo planeamiento de protección, debiéndose contemplar en él tanto los edificios unitarios como de espacios libres exteriores o interiores, otras estructuras significativas, así como los componentes naturales que lo acompañan, definiendo los tipos de intervención posible y el nivel de protección ${ }^{12}$ y, como ya hemos dicho, un valor importante en estas poblaciones es la tipología edificatoria y a la forma de ocupar la parcela, aparte claro está de los edificios singulares a los cuales ya nos hemos referido anteriormente. 


\section{Información \\ La protección de los pueblos de colonización \\ Juan Antonio Fernández Naranjo}

\section{El crecimiento}

Cómo debe crecer el poblado será uno de los problemas formales más importantes ya que, en origen, estas poblaciones estaban pensadas como cerradas, no estaba contemplado su posible crecimiento. De hecho, solían rodearse de un cinturón verde o de grandes espacios abiertos, ajardinados o no, que servían de zona intermedia entre las tierras de labor y el medio urbano. El crecimiento pues debe considerarse fuera de estas áreas de reserva que deben seguir manteniendo su carácter público y libre de edificación, sin que ello suponga que este crecimiento deba independizarse u olvidarse de la estructura de origen; por el contrario, debe partir de ella de manera que las nuevas aportaciones se mantengan dentro de la estructura general marcada por dicha estructura urbana.

\section{Epílogo}

Resulta, pues, indudable la valoración de la acción de colonización, en general, como una acción cultural que actúa sobre el territorio, que lo marca de una manera clara y potente como forma de transformación del mismo. Por lo tanto, esta colonización que nos ocupa, de 1940 a 1971 en nuestra tierra, indiscutiblemente es parte de nuestro patrimonio histórico y tendremos, pues, que considerarlo como tal, dándole carta de naturaleza oficial mediante la instrucción de los correspondientes expedientes a aquellas actuaciones de colonización que se consideren relevantes para su declaración como bien de interés cultural o su inclusión en el Catálogo General del Patrimonio Histórico de Andalucía, bien de forma especifica, bien de forma genérica.

Parece claro, además, que todo ello es independiente de las interpretaciones que se tengan que hacer dentro de la legislación vigente en esta materia. Si es patrimonio histórico, tendrá que ser acogido por dicha legislación, pero quizás sólo por pura coherencia, de manera que no se pueda entender nunca, que no todo el patrimonio histórico está contemplado por la Ley, o lo que es lo mismo, que puede existir un patrimonio histórico fuera de su marco jurídico, pensado como un marco específicamente para ello.

Dicho esto, y refiriéndonos a la protección del conjunto de patrimonio que nos ocupa, la única solución está en el urbanismo. Por un lado, porque la Ley 16/1985 de Patrimonio Histórico Español, como ya hemos visto, así lo especifica; y por otro, y éste de manera fundamental, porque es la herramienta más adecuada para ordenar el territorio, cuestión básica del tema que estamos tratando.

No obstante, el problema va a ser consecuencia de los plazos que tienen que cumplirse para la puesta en marcha del planeamiento adecuado que son, por otro lado, necesarios para garantizar la objetividad de todo el proceso. Así pues, es el periodo transitorio entre la incoación del expediente y la convalidación de dicho planeamiento el que nos va acarrear los problemas más graves.

Por todo ello se hacen necesarias varias medidas que planteen un gradiente tanto temporal como de nivel de protección, es decir que, aunque los más relevantes puedan ser declarados BIC, por abreviar, no quiere decir que el resto no pertenezca al patrimonio histórico, que sí que pertenece, pero su protección puede confiarse exclusivamente al planeamiento urbanístico adecuado, sin tener que recurrir a la legislación de patrimonio histórico.

Por lo tanto, será necesaria la elaboración previa de un detallado diagnóstico de la situación, del que se pueda determinar cuál es el estado de conservación de aquellos valores urbanos y territoriales a los que antes nos hemos referido, con lo que se podrá determinar cuáles de las zonas colonizadas pueden ser objetos de incoación de expedientes de BIC o de catalogación y cuáles no. Del primer grupo implicará el inicio del periodo transitorio (C.P.P.H.) y debería suponer además la modificación del planeamiento para su adecuada protección. Para el otro grupo, los que no son relevantes, se iniciaría sin más la modificación de su planeamiento, que tendría que tener en cuenta los criterios establecidos en la legislación patrimonial (trama urbana, modificación de alineaciones, excepcionalidad de los derribos, etc.).

El diagnóstico debe establecer además las prioridades de intervención en función de la valoración patrimonial y el grado de deterioro de la estructura territorial y urbana y, por lo tanto, fijar un plan de acción, diseñar un programa de trabajo, que debe contar con la absoluta colaboración de las administraciones implicadas (Cultura-indispensable-Ordenación del Territorio, Agricultura y Pesca, Medio Ambiente, Ayuntamientos y Diputaciones). Por lo tanto, y en definitiva, un programa preferente de la Administración Autonómica.

\section{Notas}

${ }^{1}$ Ley 16/1985 del Patrimonio Histórico Español fundamentalmente ya que la Ley 1/1991 del Patrimonio Histórico de Andalucía sólo influye en la tramitación de convalidación de los planes que los tipifica según la legislación urbanística de aplicación y tampoco nos afecta en el caso de los Conjuntos Históricos incluidos de forma específica en el Catálogo del Patrimonio Histórico de Andalucía puesto que su tramitación lo hace inviable en la práctica.

${ }^{2}$ Art. 15.3. Ley 16/1985. Conjunto Histórico es la agrupación de bienes inmuebles que forman una unidad de asentamiento, continua o dispersa, condicionada por una estructura fisica representativa de la evolución de una comunidad humana por ser testimonio de su cultura 0 constituir un valor de uso y disfrute para la colectividad. Asimismo, es Conjunto Histórico cual- 


\section{Opinión del lector}

María Yllescas Ortiz

Historiadora del Arte

quier unidad superior de población que reúna esas mismas características y pueda ser claramente delimitado.

${ }^{3}$ Art. 20. 1. Ley 16/1985. La declaración de un Conjunto Histórico, Sitio Histórico o Zona Arqueológica, como Bien de Interés Cultural, determinará la obligación para el Municipio o Municipios en que se encontraran de redactar un Plan Especial de Protección del área afectada por la declaración u otro instrumento de planeamiento de los previstos en la legislación urbanistica que cumpla en todo caso las exigencias en esta Ley establecidas. La aprobación de dicho Plan requerirá el informe favorable de la Administración competente para la protección de los bienes culturales afectados. Se entenderá emitido informe favorable transcurridos tres meses desde la presentación del Plan. La obligatoriedad de dicho Plan no podrá excusarse en la preexistencia de otro planeamiento contradictorio con la protección ni en la inexistencia previa de planeamiento general.

${ }^{4}$ Más del $80 \%$ de los temas vistos en el 2001 en toda Andalucía eran autorizaciones de licencias en Conjuntos Históricos sin planeamiento convalidado, sin contar con que no todas las licencias que se solicitaban eran sometidas a autorización, o llegando, incluso, a no exigirse la solicitud de licencia.

${ }^{5}$ Art. 20.3 Ley 16/1985. Hasta la aprobación definitiva de dicho Plan, el otorgamiento de licencias o la ejecución de las otorgadas antes de incoarse el expediente declarativo del Conjunto Histórico, Sitio Histórico o Zona Arqueológica, precisará resolución favorable de la Administración competente para la protección de los bienes afectados y, en todo caso, no se permitirán alineaciones nuevas, alteraciones en la edificabilidad, parcelaciones ni agregaciones.

${ }^{6} \mathrm{~A}$ los adjudicatarios de las parcelas se les llega a nombrar como parcelistas a la vez que colonos, puesto que muchos de ellos venían de tierras distintas a las de la zona

${ }^{7}$ Art. 17. Ley 16/1985. En la tramitación del expediente de declaración como Bien de Interés Cultural de un Conjunto Histórico deberán considerarse sus relaciones con el área territorial a que pertenece, asi como la protección de los accidentes geográficos y parajes naturales que conforman su entorno.

${ }^{8}$ Un ejemplo claro de esto son las Nuevas Poblaciones de Sierra Morena, todo un complejo sistema de pueblos con La Carolina al frente, multitud de aldeas estratégicamente situadas, una profusa red de caminos, etc. pero con dos conceptos muy presentes: una roturación del territorio mediante una clara e imperante parcelación, la suerte, y una instrumental medida de referencia, la legua.

${ }^{9}$ Art. 21.3. Ley 16/1985. La conservación de los Conjuntos Históricos declarados Bienes de Interés Cultural comporta el mantenimiento de la estructura urbana y arquitectónica, asi como de las caracteristicas generales de su ambiente.

${ }^{10}$ Art. 21.2. Ley 16/1985. Excepcionalmente, el Plan de protección de un conjunto Histórico podrá permitir remodelaciones urbanas, pero sólo en caso de que impliquen una mejora de sus relaciones con el entorno territorial o urbano o eviten los usos degradantes para el Conjunto.

${ }^{11}$ Art. 21.3. Ley 16/1985. Se considerarán excepcionales las sustituciones de inmuebles, aunque sean parciales, y sólo podrán realizarse en la medida en que contribuyan a la conservación general del carácter del Conjunto.

${ }^{12}$ Art. 21.1. Ley 16/1985. En los instrumentos de planeamiento relativos a Conjuntos Históricos se realizará la catalogación, según lo dispuesto en la legislación urbanística, de los elementos unitarios que conforman el Conjunto, tanto inmuebles edificados como espacios libres exteriores o interiores, u otras estructuras significativas, así como de los componentes naturales que lo acompañan, definiendo los tipos de intervención posible. A los elementos singulares se les dispensará una protección integral. Para el resto de los elementos se fijará, en cada caso, un nivel adecuado de protección.
¿Crees que pueden asociarse a los conceptos de patrimonio histórico/patrimonio cultural los poblados de colonización franquista? ¿Ha pasado suficiente tiempo para realizar una mirada objetiva?

Entiendo que los poblados de colonización de la época franquista forman parte inexcusable de nuestro patrimonio histórico y cultural, tanto por la valentía de su emplazamiento como por los valores arquitectónicos y urbanísticos que desarrollaron. El hecho de no haber transcurrido más de 50 años no es argumento para no integrarlos en este criterio patrimonial.

¿Existirian en dichos núcleos, diseñados por el Instituto Nacional de Colonización, valores susceptibles de conservación, protección y puesta en valor? ¿Cuáles? ¿Quién debe ocuparse de velar por ellos? ¿Has advertido algún caso de peligro inminente 0 destrucción de algunos de estos valores?

Por supuesto que existen valores susceptibles de conservación, protección y puesta en valor, ya que en muchos de dichos poblados esos valores son los que definen todo el conjunto del asentamiento asi como su materialización. Destacamos principalmente el diseño urbano, pero existen edificaciones singulares y otras de carácter seriado que deben asi mismo considerarse para su protección.

El organismo o institución que deberia velar por su protección es la Administración pública, ya que entre otras razones ella fue su promotora; pero si pasaran a tener un grado de protección. ésa deberian asumirla los organismos competentes en materia de patrimonio.

Con respecto al caso de Córdoba que es el que me toca cerca, los actuales poblados de San Antonio y de Maruanas, en el municipio de El Carpio se encuentran en buen estado de conservación, pero se está detectando un inicial uso de segunda residencia, que está conllevando una transformación de los tipos.

¿Conoces algún proyecto de intervención, inventariado o difusión del patrimonio histórico de los poblados de colonización franquistas, fundamentalmente andaluces, extremeños, aragoneses o castellano-manchegos?

No conozco ningún inventario especifico sobre estos poblados, aunque sí muchos de ellos están integrados dentro de una serie de inventarios urbanísticos. Seria muy conveniente su realización. 